\title{
Quantitative Evaluation of Mental-Health in Type-2 Diabetes Patients Through Computational Model
}

\author{
Fawaz Alassery ${ }^{1}$, Ahmed Alzahrani ${ }^{2}$, Asif Irshad Khan ${ }^{2}$, Ashi Khan ${ }^{3, *}$, Mohd Nadeem ${ }^{4}$ and \\ Md Tarique Jamal Ansari ${ }^{4}$
}

\footnotetext{
${ }^{1}$ Department of Computer Engineering, College of Computers and Information Technology, Taif University, Taif, Saudi Arabia

${ }^{2}$ Department of Computer Science, Faculty of Computing and Information Technology, King Abdulaziz University, Jeddah, 21589 , Saudi Arabia

${ }^{3}$ Department of Zoology, Dr. Ram Manohar Lohiya Avadh University, Faizabad, 224001, India

${ }^{4}$ Department of Information Technology, Babasaheb Bhimrao Ambedkar University, Lucknow, 226025, India *Corresponding Author: Ashi Khan. Email: ashikhan.phd@gmail.com Received: 03 September 2021; Accepted: 12 October 2021
}

\begin{abstract}
A large number of people live in diabetes worldwide. Type-2 Diabetes (D2) accounts for $92 \%$ of patients with D2 and puts a huge burden on the healthcare industry. This multi-criterion medical research is based on the data collected from the hospitals of Uttar Pradesh, India. In recent times there is a need for a web-based electronic system to determine the impact of mental health in D2 patients. This study will examine the impact assessment in D2 patients. This paper used the integrated methodology of Fuzzy Analytic Hierarchy (FAHP) and Fuzzy Technique for Order Performance by Similarity to Ideal Solution (FTOPSIS). The FAHP determines the impact of factors, which is classified by two levels. The first levels have three factors; Body Mass Index (BMI), Systolic Blood Pressure (SBP), and Diastolic Blood Pressure (DBP). The second level, selects the factors-age, weight, height, exercise (50 to $70 \mathrm{~min}$ ), and mental health. Furthermore, the alternatives are hospitals A1 to A6. The authors gather the data from the hospitals in different places of state Uttar Pradesh, India. The FTOPSIS approach determines the rank of alternatives. The integrated model shows the applicability and impact of data on mental health in D2 patients. This study explains the complexity of the D2 patient's condition. The multi-criterion medical research is compared with some existing methods, which confirms the strength and stability of the proposed FAHP and FTOPSIS methodology.
\end{abstract}

Keywords: Diabetes; fuzzy AHP; fuzzy TOPSIS; BMI; SBP; DBP

\section{Introduction}

Despite the fact that there has been no concurrence on the most proficient method to best describe, investigate, and type 2 Diabetes (D2) for a long time, exploration to distinguish hazard factors for diabetes has gained more huge headway. For quite a while, individuals have realized that not every person has a comparable danger for diabetes. For instance, individuals in farming nations are similarly

This work is licensed under a Creative Commons Attribution 4.0 International License, which permits unrestricted use, distribution, and reproduction in any medium, provided the original work is properly cited. 
troubled, and ethnic minorities in industrialized nations face a more serious danger. Identity, hereditary characteristics, and way of life assume a significant part in deciding individual danger factors for D2. The significance of recognizable danger factors is to advance the identification of diabetes to start hesitant measures.

Early distinguishing proof and treatment of D2 can work on the microvascular and macrovascular tangles related to this contamination. Certain terms should be characterized as the justification for this article. Hazard factors are those pieces of a person's way of life, environment, or hereditary attributes that are known to be related with an irresistible occasion through epidemiological examinations. D2 hazard factors were tried dependent on the hereditary, way of life and psychological wellness factors-Body Mass Index (BMI), Systolic Blood Pressure (SBP), Diastolic Blood Pressure (DBP) is interrelated and connected with insulin opposition and metabolic conditions. These interrelationships are portrayed in Fig. 1. Gatherings at most elevated danger are those people with a solid family ancestry, people of more seasoned age, corpulent individuals, and those who are actually latent.

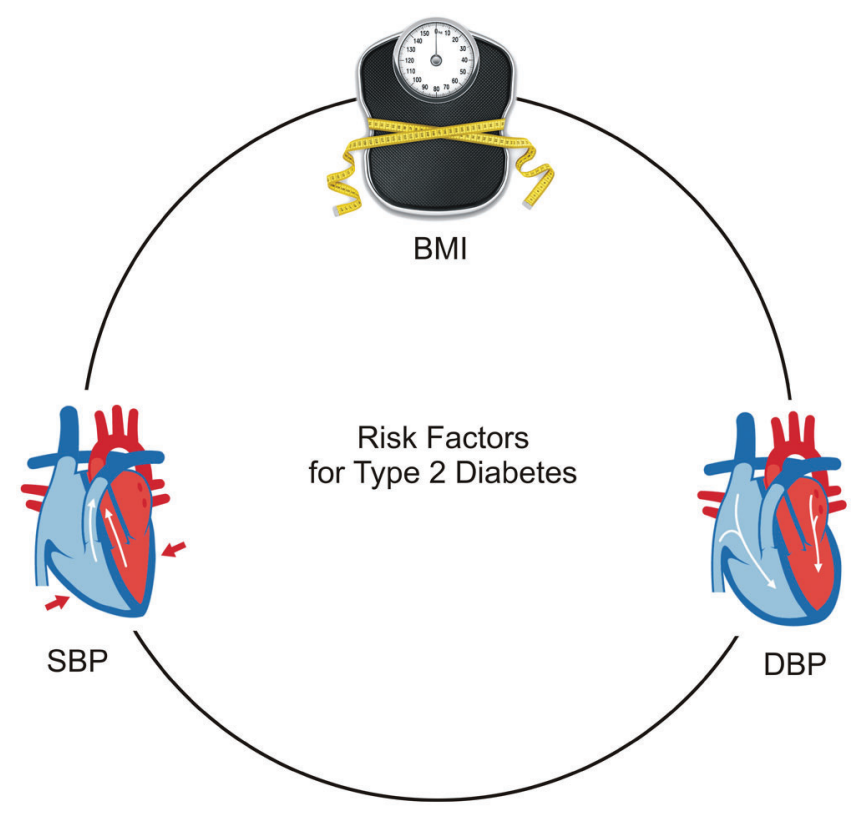

Figure 1: Risk factors for D2

As per the report of the International Diabetes Federation, roughly 422 million individuals worldwide will experience the ill effects of diabetes in 2021, and $15 \%$ of the overall prosperity costs are apportioned to complex tireless diabetes states [1]. Diabetes is a mix of metabolic issues, addressed by high glucose, brought about by shortages in action and insulin discharge.

Constant hyperglycemia of diabetes incorporates hypertension, heart and kidney disappointment, the trap of veins, feet, and eyes. Severe glucose control is fundamental for patients with D2 to keep away from the extreme climate and snare related to diabetes, for example, microvascular sickness and neuropathy in patients with D2 [2-4]. Strong eating regimens and dynamic work are taking measures to control the blood glucose levels of D2 patients [5]. In the event that the blood glucose level isn't checked through the way of life intercession, D2 patients will require a prescription as of now [6]. Also, find an optimal medication treatment pointed toward drawing out the existences of D2 patients, working on their own fulfillment, diminishing their clinical thought costs, and other fundamental subsequent utilization 
identified with D2 sicknesses. In this manner, the selection of medications for D2 patients is a significant and multi-criteria decision-making (MCDM), which is related with many credits.

According to the expanded availability to low-cost quality healthcare, medical computational techniques and data processing in recent times has attracted a great consideration [7]. MCDM procedures are one of the computational methodologies that has recently gained a lot of attention and widespread use. The chance of multi-standard fuzzy strategies is utilized and driven by Kawthankar et al. [8], and a few makers have paid colossal thought to confront the weaknesses that show up in different application fields. The fuzzy Analytic Hierarchy Process (FAHP) is utilized to decide the heaviness of components. FAHP is communicated by the level of attribution and the level of non-attribution, and the level of attribution and non-attribution are not totally equivalent. Or on the other hand identical to solidarity. In any case, there are various circumstances in MCDM connections, and in these circumstances, experts can assess the choice to meet the assessment standards. The association between complex numbers and Triangular Fuzzy Number (TFN) is the way toward picking the worth of the fuzzy number.

\section{Literature Review}

Sharawat et al. [9] have presented a study investigating the kinds of food or nutrition good for those who have diabetes. In order to explore the optimal diet for a diabetic patient, they used the AHP approach. Performance is assessed on the basis of several qualification parameters for making a meal of a diabetic patient in this nutrition. The outcome is also assessed with the fuzzy TOPSIS approach.

Zulqarnain et al. [10] investigated the TOPSIS approach and developed the TOPSIS technique model. They also conducted research for the choosing of medical clinics, which is a very important part of the disease diagnosis and treatment. In all emergencies, they determined the best medical clinic for the diagnosis of diseases utilizing the TOPSIS approach through hypothetical data in their research study.

Hasan et al. [11] provided a paradigm for the weight allocation, which examines and therefore assesses the impact of a characteristic on decision-making procedure. Their suggested framework examines previous data in the context of assessing the significance of an attribute as well as organizes the decision issues in a hierarchy organization. Mid-and relatively high weights are derived on the ground-level qualities. Collected information has validated the proposed approach. The study also discussed a number of potential uses of the weight distribution system provided.

The cross-sectional study reported by Shafii et al. [12]. Firstly, a literature review and a team of experts chosen to examine the aspects of effectiveness and took the form of an efficiency framework. Subsequently, the selected dimensions weighed through the Fuzzy AHP. Ultimately, a survey developed based on weighted evaluation metrics, and the effectiveness of CEOs in different hospitals was assessed with the Fuzzy TOPSIS.

In a study, Rajabi et al. [13] proposed control measures for violent action against medical workers utilizing the Fuzzy AHP. This study identified and prioritises preventive actions for violence against medical workers. At the first step of the process, a study of prior studies selected and abstracted the most common factors and control alternatives for violence against medical workers. In the next phase, the FAHP priority was given to selecting control measures. Ultimately, the priority was given to controlling workplace violence utilizing the fuzzy additive ratio assessment method (F-ARAS) technique.

Zarour et al. [14] presented a work aimed at describing and identifying criticalities in Saudi Arabia in particular considering the threat to the security of healthcare information through various attack statistics worldwide. A review of literature presented in order to fulfill the planned systemic literature review objective through descriptive analyses, Unit analysis as well as rating analytics. The results of ranking analysis utilizing the sophisticated technique for analytical processes provide a path for the promotion of medical records or safety in Arabic healthcare coverage by Saudi Arabic academics. 
Ansari et al. [15] designed an investigation to determine the security requirements engineering (SRE) approach best suitable for the production of assurance and confidence software, predicated on the security specialist's experience and knowledge. Use the fuzzy TOPSIS model to analyze the hierarchy. Comparisons made between efficient SRE selection processes in pairs.

All the above-mentioned research works used multi-criteria decision-making techniques to solve the challenging healthcare decision-making issues. No research employing the integrated fuzzy AHP TOPSIS approach for the quantitative evaluation of mental health in Type-2 Diabetes patients has been carried out to the best of the authors' knowledge.

\section{Type-2 Diabetes Factor}

The different factors of D2 are Body Mass Index (BMI), Systolic Blood Pressure (SBP), and Diastolic Blood Pressure (DBP) in level 1 further to evaluate the impact the authors subdivided the factors in level 2 as shown in Fig. 2 are age, weight, height, exercise (50-70 $\mathrm{min})$, and mental health.

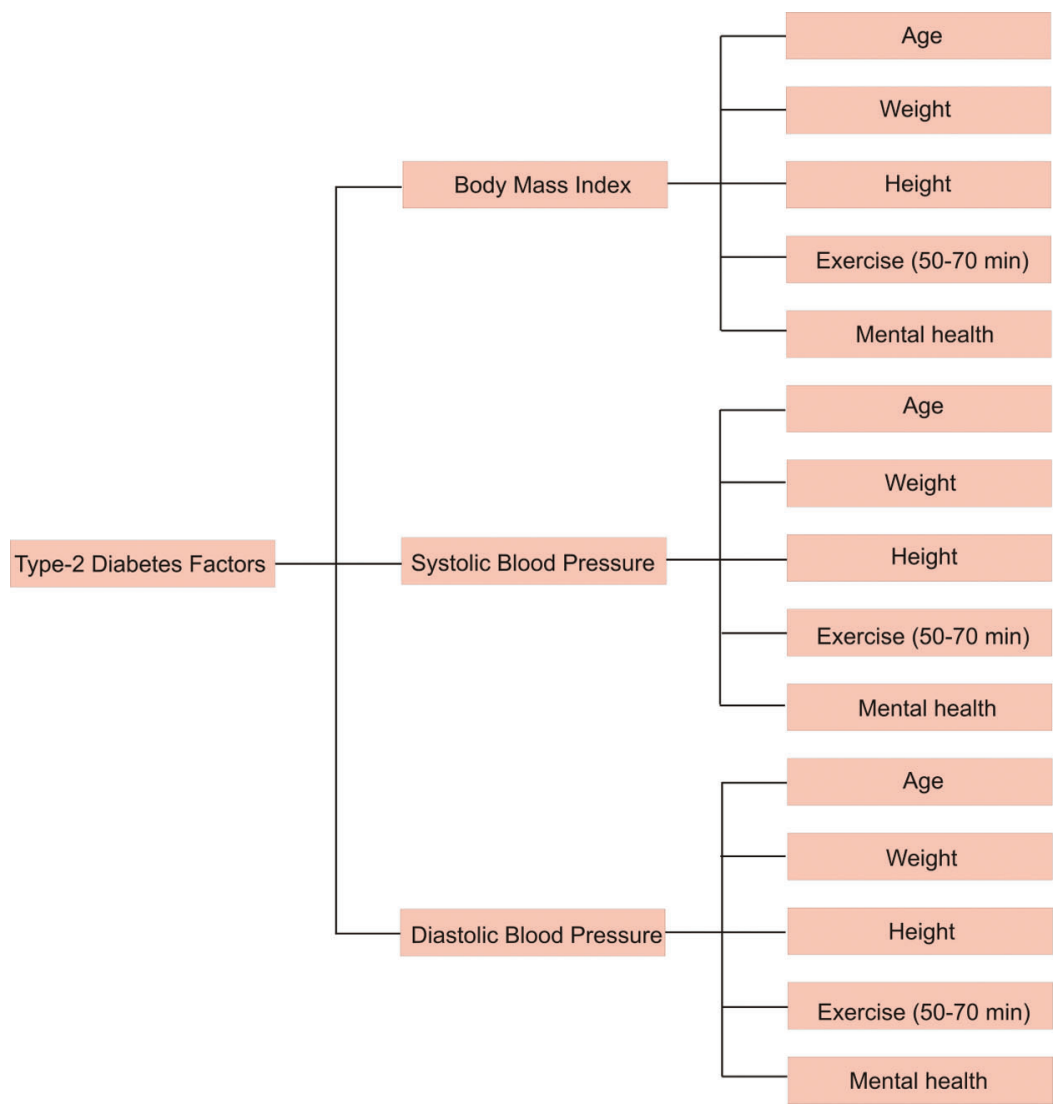

Figure 2: Two level factors for D2

Diabetes is turning into a tremendous infection on the planet since its different elements will influence a wide range of individuals and everybody. Diabetes is a persevering disease that requires progressing clinical treatment and patient self-administration direction to stay away from outrageous issues and lessen the danger of irksome issues. Diabetes patients are mind-boggling and need to manage numerous issues that should be dealt with. There are many signs that contain a progression of hindrances to re-establishing the diabetic result. These estimations of 4,444 patients are intended to convey the idea of the patient to doctors, 
patients, experts, and others, including the adherence framework, treatment region, and pinion arrangement of diabetic patients.

Albeit the inclination to scatter, all the more critically, other patient issues might require a change of targets or impressions, which is the thing that more established diabetic patients need. These characteristics are not planned to forestall further assessment and, all the more significantly, if important, different specialists in the field should treat the patient. Diabetes is an illness where the glucose level of the patient is excessively high. At the point when the degree of insulin creation in the body is diminished or the cells of the body can't handle the degree of insulin in the body, diabetes strikes anybody. Because of these issues, diabetes is a gigantic issue in the world and we should save ourselves as well as other people through certain contemplations. In case we know about when the beginning of diabetes will be abominable, then, at that point for this situation, we can save ourselves in case we are cautious. In this article, we propose another strategy to survey the squeal of diabetic patients and confirm which sorts of individuals are bound to foster diabetes by utilizing ideal game plans.

\section{Methodology}

This paper utilized the multi-model dynamic usual way of doing things for the assessment of elements in D2 and its effect on mental health. The crossover philosophy of FAHP gives the heaviness of the variables. The FTOPSIS gives indisputably the positioning of the factor concerning the current other option [16-19]. The fuzzy methodology of the accompanying philosophy is utilized in the impact assessment of the D2 on mental health. The authors select the factors of D2 and realize its impact. The FAHP and FTOPSIS approach have the appraisal of the elements in the impact assessment of the D2 [20-23]. Numerous techniques and assessment systems exist in writing and further the comprehension of the issues that make D2 and its impact on mental health. In any case, for measuring the effect of factors of D2, FAHP is the most appropriate multi rules approach. The fuzzy methodology remembered for AHP gives the most unstable size of dynamic [24-29]. Anyway, FAHP additionally has a few challenges. Hence, the authors incorporated the FTOPSIS and the dynamic way to deal with integrated FAHP and FTOPSIS. This is an exceptional technique, one of its sorts, that helps the proficient evaluation of effect factors and its other option.

\subsection{Fuzzy Analytic Hierarchy Procedure}

FAHP is a viable and authoritative technique for obviously surveying issues in the psychological wellbeing effect of D2 patients. It depends on weighting measures and significance options that should be looked at. FAHP has semantic terms and their Triangular Fuzzy Number (TFN), which address a proportion of examination [30-32]. Etymological terms have the same fuzzy numbers displayed in Tab. 1.

In this manner, the FAHP program assesses every substance utilized by the expert. The following stage is the Triangular Fuzzy Number of the various leveled structure. The factor impact and the decision of estimation for various elective principles have a solitary factor pairwise connection, which accepts a critical piece of the succession. The subsequent FAHP step utilizes fuzzy examination measures to change the numerical worth of language terms [33-35]. The FAHP program is utilized to decide the heaviness of parts. The means are as per the following:

Stage 1: The three-sided fuzzy number drives the enrollment capacity, and the yes or no rationale is conveyed among the different sub-values in Tab. 1. The enrollment work is displayed in Eq. (1).

$$
\mu_{\mathrm{a}}(\mathrm{x})=\mathrm{a} \rightarrow[0,1]
$$


Table 1: Fuzzy comparison measures or triangular fuzzy numbers

\begin{tabular}{ll}
\hline Linguistic terms & TFN \\
\hline Equal & $(1,1,1)$ \\
Not bad & $(2,3,4)$ \\
Good & $(4,5,6)$ \\
Very good & $(6,7,8)$ \\
Perfect & $(9,9,9)$ \\
Weak advantage & $(1,2,3)$ \\
Preferable & $(3,4,5)$ \\
Fairly good & $(5,6,7)$ \\
Absolute & $(7,8,9)$ \\
\hline
\end{tabular}

Allow us to pick the most reduced worth of ' 1 ', the normal worth of 'mi', and the most elevated worth of ' $u$ ' as displayed in Fig. 3.

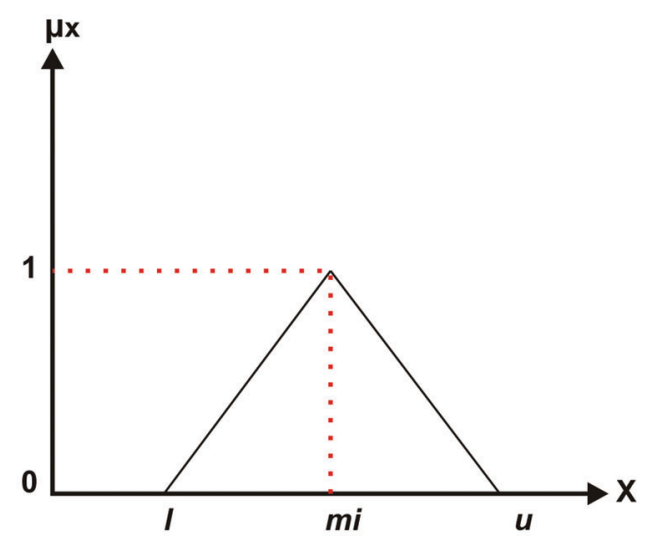

Figure 3: Triangular fuzzy number

Stage 2: Then, assess the lattice and convert the language terms into Triangular Fuzzy Numbers. The TFN measure is assessed by looking at the numerical mathematical mean. The mathematical mean is utilized to assess the meaning of the outcomes between the components.

Stage 3: What's more, assessed the two-dimensional examination interaction of the fuzzy pair correlation lattice, which was gotten from Eqs. (2) and (3).

$$
\begin{aligned}
& \widetilde{\mathrm{A}^{\mathrm{d}}}=\left[\tilde{k}_{11}^{d} \tilde{k}_{12}^{d} \ldots \tilde{k}_{1 n}^{d} \tilde{k}_{21}^{d} \tilde{k}_{22}^{d} \ldots \tilde{k}_{2 n}^{d} \ldots \ldots \ldots \tilde{k}_{n 1}^{d} \tilde{k}_{n 2}^{d} \ldots \tilde{k}_{n n}^{d}\right] \\
\tilde{k}_{i j}= & \sum_{d=1}^{d} \tilde{k}_{i j}^{d}
\end{aligned}
$$

where, $\widetilde{k_{i j}^{k}}$, specifies that the leader ' $\mathrm{d}$ ' is in the condition meager conditions 2 and 3 . In the event that the inclination is more prominent than 1 , the normal worth is chosen. 
Stage 4: Assess normal inclinations and make a chain of command of impact factors. As per Eq. (4), a pairwise examination framework is formed for all factors that impact the progressive system as per inclination.

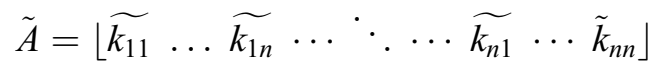

Step 5: The geometric mean and fuzzy weight of factors are derived by Eq. (5), which shows the geometric mean technique; Eq. (6), derives the fuzzy weight of factors.

$\tilde{p}_{i}=\left(\prod_{j=1}^{n} \tilde{k}_{i j}\right)^{\frac{1}{n}}, \quad i=1,2,3 \ldots n$

$\tilde{w}_{i}=\tilde{p}_{i} \otimes\left(\tilde{p}_{1} \oplus \tilde{p}_{2} \oplus \tilde{p}_{3} \ldots \oplus \tilde{p}_{n}\right)^{-1}$

Step 6: Further, drive and evaluate the normalized weight criteria from Eqs. (7) and (8).

$M_{i}=\frac{\tilde{w}_{1} \oplus \tilde{w}_{2} \ldots \ldots \oplus \tilde{w}_{n}}{n}$

$N r_{i}=\frac{M_{i}}{M_{1} \oplus M_{2} \oplus \ldots \ldots \oplus M_{n}}$

Step 7: Calculate the Best Non-fuzzy recital. The center of area methods are mention here which is the Best Non-fuzzy Performance (BNP); the association and effect of the fuzzy weights of all metrics are calculated by Eq. (9).

$$
B N P w D 1=\frac{[(u w 1-l w 1)+(m i w 1-l w 1)]}{3}+l w 1
$$

\subsection{Fuzzy TOPSIS}

The "M" alternative in the plane of numerical math with the point "M" and the TOPSIS interaction of the dimensional region " $\mathrm{N}$ " are utilized to choose different situating measures. The TOPSIS procedure is primarily founded on the chance of outright detachment, without veering off from the positive ideal course of action, and the negative ideal reaction to the ideal and not exactly ideal plans, alone. The TOPSIS technique is significant for allocating different alternatives to ideal circumstances and elements identified with rules [36-39]. To accomplish consistency with fuzzy climate, TOPSIS downsizes the fuzzy number to the one addressed by the slant and settles the significance of the model. The authors picked the half-and-half techniques for FAHPFTOPSIS, which are aggregate decision dynamic strategies under a diffuse environment. The FTOPSIS innovation has the accompanying advances:

Step 1: Through the extra assessment of the factor range by FTOPSIS, the FAHP strategy assesses the heaviness of the factor and assesses the heaviness of the factor as per the options chosen from conditions 1 to 9 above.

Step 2: In FTOPSIS, first, infer the impacting factors and the language glossary utilized in the options from Tab. 2 referenced beneath. One can likewise utilize the fuzzy choice grid with the assistance of Eq. (10) and assess the framework. 


$$
\begin{aligned}
& \begin{array}{llll}
C_{1} & \ldots \ldots & C_{n}
\end{array} \\
& \tilde{K}=\ldots \begin{array}{c}
A_{1} \\
A_{m}
\end{array}\left[\begin{array}{ccc}
\tilde{x}_{11} & \cdots & \tilde{x}_{1 n} \\
\ldots & \ddots & \ldots \\
\tilde{x}_{m 1} & \cdots & \tilde{x}_{m n}
\end{array}\right]
\end{aligned}
$$

Table 2: Linguistic terms and its triangular fuzzy number

\begin{tabular}{ll}
\hline Variable & Resultant TFN \\
\hline Very meager & $(0,1,3)$ \\
Meager & $(1,3,5)$ \\
Pale & $(3,5,7)$ \\
Fine & $(5,7,9)$ \\
Very fine & $(7,9,10)$ \\
\hline
\end{tabular}

Here, $\tilde{x}_{i j}=\frac{1}{D}\left(\tilde{x}_{i j}^{1} \cdots \oplus \tilde{x}_{i j}^{d} \oplus \cdots \tilde{x}_{i j}^{D}\right), \tilde{x}_{i j}^{d}$, perform the ranking of alternative $A_{i}$, the factors $C_{J}$ is evaluated by the $d^{\text {th }}$ practitioner $\tilde{x}_{i j}^{d}=\left(l_{i j}^{d}, m i_{i j}^{d}\right.$, $\left.u_{i j}^{d}\right)$.

Step 3: The normalized fuzzy decision matrix is evaluated by Eq. (11), represented by $\tilde{P}$. The normalization is calculated by Eq. (12).

$\tilde{P}=\left[\tilde{p}_{i j}\right]_{m \times n}$

$\tilde{p}_{i j}=\left(\frac{l_{i j}}{u_{j}^{+}}, \frac{m i_{i j}}{u_{j}^{+}}, \frac{u_{i j}}{u_{j}^{+}}\right), \quad u_{j}^{+}=\max \left\{u_{i j}, \quad i=1,2,3 . . n\right\}$

The most expected level $u_{j}^{+}$is 1 and the worst is 0 . The normalization processes of TFNs are calculated by similar steps.

Step 4: Further, the weighted normalized fuzzy decision matrix $(\tilde{Q})$ is quantified by Eq. (13).

$\tilde{Q}=\left[\tilde{q}_{i j}\right]_{m \times n} i=1,2, . . m j=1,2,3 \ldots n$

where, $\tilde{q}_{i j}=\tilde{p}_{i j} \otimes \tilde{w}_{i j}$

Step 5: The fuzzy positive ideal clarification ' $\mathrm{A}+$ ' and fuzzy negative ideal clarification ' $\mathrm{A}$-' are calculated as the best and worst solution respectively by the Eqs. (14) and (15). This can be done due to avoiding the irregular complication of calculation.

$$
\begin{aligned}
& A^{+}=\left(\tilde{q}_{1, \ldots \ldots . .}^{*} \tilde{q}_{j, \ldots \ldots .}^{*} \tilde{q}_{n,}^{*}\right) \\
& A^{-}=\left(\tilde{q}_{1, \ldots \ldots}^{*} \ldots \tilde{q}_{j, \ldots \ldots . . .}^{*} \tilde{q}_{n,}^{*}\right)
\end{aligned}
$$


The detachments of alternative are calculated by the Eqs. (16) and (17) respectively.

$\tilde{d}_{i}^{+}=\sum_{j=1}^{n} d\left(\tilde{q}_{i j}, \tilde{q}_{i j}^{*}\right), \quad i=1,2, . . m j=1,2,3 \ldots n$

$\tilde{d}_{i}^{-}=\sum_{j=1}^{n} d\left(\tilde{q}_{i j}, \tilde{q}_{i j}^{*}\right), \quad i=1,2, . . m j=1,2,3 \ldots n$

Step 6: Also, the estimation of the closeness factor addressing the $C \tilde{C}_{i}$, is characterized as the general pressure of the option in contrast to the effect of emotional well-being in the patient D2. It is assessed by Eq. (18). The closeness coefficient comprises an option in contrast to the accomplishment of the ideal methodology level. The sequence factor assesses the degree of a diffuse hole at the beginning of diffuse admittance to recuperate the choice $[40,41]$.

$$
C \tilde{C}_{i}=\frac{\tilde{k}_{i}^{-}}{\tilde{k}_{i}^{+}+\tilde{k}_{i}^{-}}=1-\frac{\tilde{k}_{i}^{+}}{\tilde{k}_{i}^{+}+k_{i}^{-}}, i=1,2, \ldots, m
$$

The ranks of alternatives are determined by Eq. (18), by using the detachments. Further, the calculation of the impact on mental health in D2 patients with the help of factors and its selected alternatives is done and the numerical analysis is explained in the next section of the paper.

\section{Numerical Analysis and Results}

Tabs. 3-5 show the triangular pairwise matrices, normalize weights, local weights, and global weights through the hierarchy of the factors created by the Eqs. (1)-(9). By using the Eqs. (10)-(13), authors estimated the subjective cognition outcomes, normalized fuzzy-decision matrix, the weighted normalized fuzzy-decision matrix that are shown in Tabs. 6 and 7, respectively. With the help of Eqs. (14)-(18), the authors estimated the closeness coefficients as shown in Tab. 8 and Fig. 4.

Table 3: Triangular fuzzy pair-wise comparison matrix at level 1

\begin{tabular}{llll}
\hline & F1 & F2 & F3 \\
\hline F1 & $1.000000,1.000000,1.000000,1.000000$ & $1.000000,1.000000,3.000000,5.000000$ & $0.330000,1.000000,1.000000,3.000000$ \\
F2 & $0.200000,0.330000,1.000000,1.000000$ & $1.000000,1.000000,1.000000,1.000000$ & $0.200000,0.330000,1.000000,1.000000$ \\
F3 & $0.330000,1.000000,1.000000,3.000000$ & $1.000000,1.000000,3.000000,5.000000$ & $1.000000,1.000000,1.000000,1.000000$ \\
\hline
\end{tabular}

Table 4: Normalized weights of level 1 factors

\begin{tabular}{llll}
\hline & Geometric means & Fuzzify local weights & Defuzzified weights \\
\hline F1 & $0.691200,1.000000,1.400400,2.470000$ & $0.120000,0.200600,0.500800,1.430000$ & 0.530083 \\
F2 & $0.340000,0.480000,1.000000,1.000000$ & $0.060000,0.120000,0.400000,0.600000$ & 0.280033 \\
F3 & $0.700000,1.000000,1.400000,2.500000$ & $0.120000,0.250000,0.500700,1.420000$ & 0.530000 \\
\hline
\end{tabular}

Based upon the findings of this research study the relative closeness (Rci) of different alternatives A1, A2, A3, A4, A5, and A6 are 0.30925658, 0.30785473, 0.27859855, 0.29556587, 0.24566598, and 0.25666987 respectively. Alternative A1 having the highest Rci value. 
Table 5: Global weights through the hierarchy

\begin{tabular}{|c|c|c|c|c|c|c|}
\hline $\begin{array}{l}\text { Factors of } \\
\text { level } 1\end{array}$ & Local weights & $\begin{array}{l}\text { Factors of } \\
\text { level } 2\end{array}$ & Local weights & Global weights & $\begin{array}{l}\text { Defuzzified } \\
\text { weights }\end{array}$ & $\begin{array}{l}\text { Normalized } \\
\text { weights }\end{array}$ \\
\hline \multirow[t]{5}{*}{$\mathrm{F} 1$} & $\begin{array}{l}0.120000,0.260000 \\
0.580000,1.430000\end{array}$ & F11 & $\begin{array}{l}0.051200,0.161240 \\
0.283110,1.011140\end{array}$ & $\begin{array}{l}0.012060,0.015420 \\
0.125650,1.455470\end{array}$ & 0.311650 & 0.093890 \\
\hline & & F12 & $\begin{array}{l}0.031145,0.165116 \\
0.225116,0.620110\end{array}$ & $\begin{array}{l}0.004540,0.042630, \\
0.133510,0.885850\end{array}$ & 0.206560 & 0.062740 \\
\hline & & F13 & $\begin{array}{l}0.051190,0.208110 \\
0.342280,1.262230\end{array}$ & $\begin{array}{l}0.004570,0.055840 \\
0.205520,1.807520\end{array}$ & 0.387360 & 0.120760 \\
\hline & & F14 & $\begin{array}{l}0.051140,0.133330 \\
0.283310,0.948330\end{array}$ & $\begin{array}{l}0.004560,0.035640 \\
0.158640,1.357830\end{array}$ & 0.292780 & 0.058760 \\
\hline & & F15 & $\begin{array}{l}0.033440,0.086440, \\
0.181550,0.498025\end{array}$ & $\begin{array}{l}0.008540,0.029820 \\
0.108750,0.711560\end{array}$ & 0.162560 & 0.049560 \\
\hline \multirow[t]{5}{*}{$\mathrm{F} 2$} & $\begin{array}{l}0.006000,0.120000 \\
0.400000,0.612000\end{array}$ & F21 & $\begin{array}{l}0.048540,0.154470 \\
0.271470,1.025850\end{array}$ & $\begin{array}{l}0.005660,0.045300 \\
0.155370,1.465820\end{array}$ & 0.311890 & 0.091780 \\
\hline & & F22 & $\begin{array}{l}0.033450,0.129440, \\
0.212460,0.781470\end{array}$ & $\begin{array}{l}0.007440,0.036530 \\
0.127430,1.114460\end{array}$ & 0.239850 & 0.078820 \\
\hline & & F23 & $\begin{array}{l}0.064440,0.247400, \\
0.426140,1.214440\end{array}$ & $\begin{array}{l}0.008570,0.062530, \\
0.248950,1.732780\end{array}$ & 0.393560 & 0.114950 \\
\hline & & F24 & $\begin{array}{l}0.052440,0.159440, \\
0.297750,1.025560\end{array}$ & $\begin{array}{l}0.008560,0.041450 \\
0.173850,1.462470\end{array}$ & 0.316740 & 0.093510 \\
\hline & & F25 & $\begin{array}{l}0.026520,0.075530 \\
0.115330,0.505530\end{array}$ & $\begin{array}{l}0.003740,0.014590 \\
0.066580,0.714480\end{array}$ & 0.148140 & 0.044530 \\
\hline \multirow[t]{5}{*}{ F3 } & $\begin{array}{l}0.1200,0.2500,0.5700 \\
1.4200\end{array}$ & F31 & $\begin{array}{l}0.035510,0.075580 \\
0.125510,0.395550\end{array}$ & $\begin{array}{l}0.002560,0.016500 \\
0.049550,0.225560\end{array}$ & 0.057350 & 0.016290 \\
\hline & & F32 & $\begin{array}{l}0.149880,0.278960 \\
0.723880,1.508890\end{array}$ & $\begin{array}{l}0.009580,0.034860 \\
0.292770,0.873780\end{array}$ & 0.255560 & 0.077730 \\
\hline & & F33 & $\begin{array}{l}0.078860,0.218880, \\
0.455880,1.031880\end{array}$ & $\begin{array}{l}0.004980,0.027860 \\
0.183360,0.592560\end{array}$ & 0.177400 & 0.051740 \\
\hline & & F34 & $\begin{array}{l}0.035880,0.097770 \\
0.198780,0.513980\end{array}$ & $\begin{array}{l}0.002890,0.012650 \\
0.080750,0.297570\end{array}$ & 0.080750 & 0.024560 \\
\hline & & F35 & $\begin{array}{l}0.031260,0.078580 \\
0.121560,0.395850\end{array}$ & $\begin{array}{l}0.002750,0.010560 \\
0.049530,0.225780\end{array}$ & 0.042650 & 0.036680 \\
\hline
\end{tabular}

Table 6: Subjective cognition results of evaluators in linguistic terms

\begin{tabular}{lllllll}
\hline $\begin{array}{l}\text { Factors/ } \\
\text { Alternatives }\end{array}$ & A1 & A2 & A3 & A4 & A5 \\
\hline F11 & $3.0000,5.0000$, & $3.0000,5.0000$, & $2.1800,4.0900$, & $2.8200,4.6400$, & $1.9100,3.7300$, & $2.4500,4.2700$, \\
& $7.1400,7.5100$ & $7.1400,7.5100$ & $6.1400,7.5100$ & $6.6400,8.5100$ & $5.7300,7.5100$ & $6.2700,8.6200$ \\
F12 & $3.7300,5.7300$, & $3.0000,5.0000$, & $3.0000,5.0000$, & $2.1800,4.0900$, & $2.8200,4.6400$, & $1.9100,3.7300$, \\
& $7.5500,8.6500$ & $7.1400,7.5100$ & $7.1400,7.5100$ & $6.1400,7.5100$ & $6.6400,8.5100$ & $5.7300,7.5100$ \\
F13 & $3.0000,5.0000$, & $2.1800,4.0900$, & $2.8200,4.6400$, & $1.9100,3.7300$, & $1.9100,3.7300$, & $2.4500,4.2700$, \\
& $7.1400,7.5100$ & $6.1400,7.5100$ & $6.6400,8.5100$ & $5.7300,7.5100$ & $5.7300,7.5100$ & $6.2700,8.6500$ \\
F14 & $3.7300,5.7300$, & $3.0000,5.0000$, & $3.0000,5.0000$, & $2.1800,4.0900$, & $2.8200,4.6400$, & $1.9100,3.7300$, \\
& $7.5500,8.6500$ & $7.1400,7.5100$ & $7.1400,7.5100$ & $6.1400,7.5100$ & $6.6400,8.5100$ & $5.7300,7.5100$ \\
F15 & $3.0000,5.0000$, & $2.1800,4.0900$, & $2.8200,4.6400$, & $1.9100,3.7300$, & $0.9100,2.4500$, & $2.4500,4.2700$, \\
& $7.1400,7.5100$ & $6.1400,7.5100$ & $6.6400,8.5100$ & $5.7300,7.5100$ & $4.4500,5.6500$ & $6.2700,8.6500$ \\
F21 & $3.7300,5.7300$, & $3.0000,5.0000$, & $3.0000,5.0000$, & $2.1800,4.0900$, & $2.8200,4.6400$, & $1.9100,3.7300$, \\
& $7.5500,8.6500$ & $7.1400,7.5100$ & $7.1400,7.5100$ & $6.1400,7.5100$ & $6.6400,8.5100$ & $5.7300,7.5100$ \\
\hline
\end{tabular}


IASC, 2022, vol.32, no.3

\begin{tabular}{|c|c|c|c|c|c|c|}
\hline $\begin{array}{l}\text { Factors/ } \\
\text { Alternatives }\end{array}$ & A1 & A2 & $\mathrm{A} 3$ & A4 & A5 & A6 \\
\hline F22 & $\begin{array}{l}3.7300,5.7300 \\
7.5500,8.6500\end{array}$ & $\begin{array}{l}3.7300,5.7300 \\
7.5500,8.6500\end{array}$ & $\begin{array}{l}3.7300,5.7300 \\
7.5500,8.6500\end{array}$ & $\begin{array}{l}2.4500,4.4500 \\
6.4500,7.6500\end{array}$ & $\begin{array}{l}0.9100,2.4500 \\
4.4500,5.6500\end{array}$ & $\begin{array}{l}2.4500,4.2700 \\
6.2700,8.6500\end{array}$ \\
\hline F23 & $\begin{array}{l}3.7300,5.7300 \\
7.5500,8.6500\end{array}$ & $\begin{array}{l}3.0000,5.0000 \\
7.1400,7.5100\end{array}$ & $\begin{array}{l}2.1800,4.0900 \\
6.1400,7.5100\end{array}$ & $\begin{array}{l}2.8200,4.6400, \\
6.6400,8.5100\end{array}$ & $\begin{array}{l}1.9100,3.7300, \\
5.7300,7.5100\end{array}$ & $\begin{array}{l}2.4500,4.2700, \\
6.2700,8.6500\end{array}$ \\
\hline F24 & $\begin{array}{l}3.0000,5.0000 \\
7.1400,7.5100\end{array}$ & $\begin{array}{l}2.1800,4.0900 \\
6.1400,7.5100\end{array}$ & $\begin{array}{l}2.8200,4.6400 \\
6.6400,8.5100\end{array}$ & $\begin{array}{l}1.9100,3.7300 \\
5.7300,7.5100\end{array}$ & $\begin{array}{l}2.4500,4.2700 \\
6.2700,8.6500\end{array}$ & $\begin{array}{l}2.4500,4.2700, \\
6.2700,8.6500\end{array}$ \\
\hline F25 & $\begin{array}{l}3.7300,5.7300 \\
7.5500,8.6500\end{array}$ & $\begin{array}{l}3.0000,5.0000 \\
7.1400,7.5100\end{array}$ & $\begin{array}{l}3.0000,5.0000 \\
7.1400,7.5100\end{array}$ & $\begin{array}{l}2.1800,4.0900 \\
6.1400,7.5100\end{array}$ & $\begin{array}{l}2.8200,4.6400 \\
6.6400,8.5100\end{array}$ & $\begin{array}{l}1.9100,3.7300 \\
5.7300,7.5100\end{array}$ \\
\hline F31 & $\begin{array}{l}3.7300,5.7300 \\
7.5500,8.6500\end{array}$ & $\begin{array}{l}3.7300,5.7300 \\
7.5500,8.6500\end{array}$ & $\begin{array}{l}3.7300,5.7300 \\
7.5500,8.6500\end{array}$ & $\begin{array}{l}2.4500,4.4500 \\
6.4500,7.6500\end{array}$ & $\begin{array}{l}0.9100,2.4500 \\
4.4500,5.6500\end{array}$ & $\begin{array}{l}2.4500,4.2700 \\
6.2700,8.6500\end{array}$ \\
\hline F32 & $\begin{array}{l}3.0000,5.0000 \\
7.1400,7.5100\end{array}$ & $\begin{array}{l}3.0000,5.0000 \\
7.1400,7.5100\end{array}$ & $\begin{array}{l}2.1800,4.0900 \\
6.1400,7.5100\end{array}$ & $\begin{array}{l}2.8200,4.6400 \\
6.6400,8.5100\end{array}$ & $\begin{array}{l}1.9100,3.7300 \\
5.7300,7.5100\end{array}$ & $\begin{array}{l}2.4500,4.2700 \\
6.2700,8.6500\end{array}$ \\
\hline F33 & $\begin{array}{l}3.7300,5.7300 \\
7.5500,8.6500\end{array}$ & $\begin{array}{l}3.7300,5.7300 \\
7.5500,8.6500\end{array}$ & $\begin{array}{l}3.0000,5.0000 \\
7.1400,7.5100\end{array}$ & $\begin{array}{l}2.1800,4.0900 \\
6.1400,7.5100\end{array}$ & $\begin{array}{l}2.8200,4.6400 \\
6.6400,8.5100\end{array}$ & $\begin{array}{l}1.9100,3.7300 \\
5.7300,7.5100\end{array}$ \\
\hline F34 & $\begin{array}{l}3.7300,5.7300 \\
7.5500,8.6500\end{array}$ & $\begin{array}{l}3.7300,5.7300 \\
7.5500,8.6500\end{array}$ & $\begin{array}{l}3.7300,5.7300 \\
7.5500,8.6500\end{array}$ & $\begin{array}{l}2.4500,4.4500 \\
6.4500,7.6500\end{array}$ & $\begin{array}{l}0.9100,2.4500 \\
4.4500,5.6500\end{array}$ & $\begin{array}{l}2.4500,4.2700 \\
6.2700,8.6500\end{array}$ \\
\hline F35 & $\begin{array}{l}3.7300,5.7300 \\
7.5500,8.6500\end{array}$ & $\begin{array}{l}3.7300,5.7300 \\
7.5500,8.6500\end{array}$ & $\begin{array}{l}3.7300,5.7300 \\
7.5500,8.6500\end{array}$ & $\begin{array}{l}2.4500,4.4500 \\
6.4500,7.6500\end{array}$ & $\begin{array}{l}0.9100,2.4500, \\
4.4500,5.6500\end{array}$ & $\begin{array}{l}2.4500,4.2700 \\
6.2700,8.6500\end{array}$ \\
\hline
\end{tabular}

Table 7: Distance between alternatives and ideal solutions

\begin{tabular}{|c|c|c|c|c|c|c|c|c|c|c|c|c|}
\hline \multirow[b]{2}{*}{ Factors/Alternatives } & \multicolumn{6}{|c|}{ Positive ideal solutions } & \multicolumn{6}{|c|}{ Negative ideal solutions } \\
\hline & A1 & $\mathrm{A} 2$ & A3 & A4 & A5 & A6 & A1 & $\mathrm{A} 2$ & $\mathrm{~A} 3$ & A4 & A5 & A6 \\
\hline F11 & 0.9580 & 0.8990 & 0.9080 & 0.9290 & 0.9190 & 0.9400 & 0.1850 & 0.0950 & 0.1850 & 0.0950 & 0.0920 & 0.0600 \\
\hline $\mathrm{F} 12$ & 0.8470 & 0.9110 & 0.9110 & 0.9580 & 0.8990 & 0.9080 & 0.1730 & 0.1850 & 0.1730 & 0.0720 & 0.0640 & 0.0590 \\
\hline F13 & 0.9110 & 0.9110 & 0.9580 & 0.8990 & 0.9080 & 0.9110 & 0.1850 & 0.1730 & 0.0720 & 0.0640 & 0.0950 & 0.0920 \\
\hline F14 & 0.8990 & 0.9080 & 0.8470 & 0.9110 & 0.9110 & 0.8940 & 0.1850 & 0.1730 & 0.1850 & 0.1730 & 0.0720 & 0.0640 \\
\hline F15 & 0.9110 & 0.9110 & 0.9410 & 0.8640 & 0.8940 & 0.9080 & 0.1730 & 0.0420 & 0.1730 & 0.0420 & 0.1850 & 0.0950 \\
\hline $\mathrm{F} 21$ & 0.9580 & 0.8990 & 0.9110 & 0.9110 & 0.9580 & 0.8990 & 0.1850 & 0.1730 & 0.0720 & 0.0640 & 0.1730 & 0.0720 \\
\hline F22 & 0.9110 & 0.9110 & 0.8990 & 0.9080 & 0.8470 & 0.9110 & 0.1850 & 0.1730 & 0.0720 & 0.0640 & 0.0720 & 0.0640 \\
\hline F23 & 0.8990 & 0.9080 & 0.9110 & 0.9110 & 0.9410 & 0.8640 & 0.1730 & 0.0420 & 0.1850 & 0.0950 & 0.1850 & 0.0950 \\
\hline F24 & 0.9110 & 0.9110 & 0.9580 & 0.8990 & 0.9080 & 0.8990 & 0.1850 & 0.1730 & 0.1850 & 0.1730 & 0.0720 & 0.0640 \\
\hline F25 & 0.8990 & 0.9080 & 0.8470 & 0.9110 & 0.9110 & 0.9110 & 0.1730 & 0.0720 & 0.1730 & 0.0720 & 0.0640 & 0.0950 \\
\hline F31 & 0.9110 & 0.9110 & 0.9110 & 0.9580 & 0.8990 & 0.9080 & 0.1730 & 0.1850 & 0.1730 & 0.1850 & 0.1730 & 0.0720 \\
\hline F32 & 0.9110 & 0.9110 & 0.9580 & 0.8990 & 0.9080 & 0.9110 & 0.0420 & 0.1730 & 0.0420 & 0.1730 & 0.0420 & 0.1850 \\
\hline F33 & 0.8990 & 0.9080 & 0.8470 & 0.9110 & 0.9110 & 0.8940 & 0.1730 & 0.0720 & 0.1730 & 0.0720 & 0.0640 & 0.1730 \\
\hline F34 & 0.9110 & 0.9110 & 0.9410 & 0.8640 & 0.8940 & 0.9080 & 0.1730 & 0.0720 & 0.1730 & 0.0720 & 0.0640 & 0.0720 \\
\hline F35 & 0.9580 & 0.8990 & 0.9580 & 0.8990 & 0.9080 & 0.9110 & 0.0420 & 0.1850 & 0.0420 & 0.1850 & 0.0950 & 0.1850 \\
\hline
\end{tabular}

Table 8: Relative closeness of the alternatives

\begin{tabular}{lllllll}
\hline Alternatives & A1 & A2 & A3 & A4 & A5 & A6 \\
\hline Relative closeness (Rci) & 0.30925658 & 0.30785473 & 0.27859855 & 0.29556587 & 0.24566598 & 0.25666987 \\
\hline
\end{tabular}




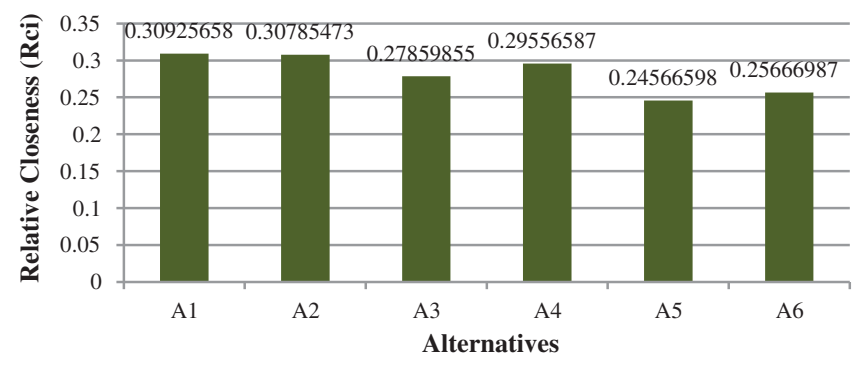

Figure 4: Relative closeness of the alternatives

\section{Conclusions}

The integrated decision-making approach for the impact on mental health due to the D2, BMI factor has the highest weight and the Relative Closeness (RCi) of A1 alternative data from the hospital is considered as the most significant entity for the impact of mental health due to the D2. The proof base for the best administration of D2 is developing quickly, can give successful multidisciplinary care after an early analysis. Despite this, numerous patients actually experience genuine and dangerous microvascular and macrovascular complexities. The counteraction of D2 is conceivable and ought to endeavor through a broad public counteraction plan. When diabetes happens, treatment should zero in on the patient's necessities and circumstances, and effectively deal with the individuals who are probably going to profit with treatment. Some other studies also show patients with type 2 diabetes have increased BMI [42]. The frequency, although increasing with higher BMI of diabetes mellitus, hypertension, and dyslipidemia in investigations seen in all BMI categories [43].

In any case, apparently hereditary variables are likewise significant. As exhibited in a new investigation, factors, for example, BMI was changed and tracked down that the danger of D2 is still raised among patients. Anyway, even at the point when the impacts on mental health and stoutness are perceived by, the most grounded indicators of D2 are high fasting insulin focus and low insulin discharge. These discoveries might reinforce endeavors to recognize powerless people from any public ethnic gathering or populace and may permit the improvement of explicit essential anticipation programs for D2.

The target of the investigation is to utilize blended innovation of numerous models Combining the fuzzy insightful order measure and fuzzy TOPSIS to assess a gathering of clinic site choices to accomplish the best options that address the issues and assumptions for customers. The outcomes show that medical clinics should focus closer on specialization, intelligence, and administration precision (unacceptable); unwavering quality and responsiveness (primary norm) to perform good and qualified Web administrations. There, the AHP and TOPSIS techniques execute in a fuzzy climate to tackle this trouble. Numerous other multitrait assessment strategies can be utilized to assess the nature of electronic medical care administrations i.e., breaking down network measures [18-25]. Further exploration might be the application and result from the examination of the integrated strategy consolidating AHP and TOPSIS techniques in QoS execution issues.

The model can likewise be applied to different examinations to explore client impressions of the nature of electronic administrations also, assess how changes over the long run. This technique doesn't expect transformation to limit the norm; hence, there is no bending in the information change; this technique is intended to assess a solitary other option; (a) every choice and optimal the distinction between or hostile to ideal choices can be explained in the strategy created by as "utility degree"; (b) The certainty level of BMI is thought of, mirroring the certainty of its choice, and enhancing the variety of choice data sex. Moreover, the proposed strategy has a few shortcomings: (a) Compared to the TOPSIS strategy different proposed by might be less steady notwithstanding changes in the information; (b) therefore, might be 
touchy to slight changes in the information, and the venture arrangement might be not the same as the characterization acquired by various strategies.

There are numerous opportunities for future exploration. The quantitative results achieved by FAHP and FTOPSIS will support the experts in ordering higher situated parts of a product in the board structure.

FAHP strategy gives the weight of the factors; FTOPSIS gives the position or rank of the accompanying alternatives in the $\mathrm{D} 2$ patients.

Impact on mental health in D2 patients should be the preeminent need for both future examinations and present undertakings to enhance the adequacy of patients. Improvement rules can be conveyed over this evaluation to help the specialists in refining the construction of safety using high coordinated angles in concern. This mental health assessment may have a couple of delimits which can be crushed later in future examinations.

Acknowledgement: We deeply acknowledge Taif University for supporting this study through Taif University Researchers Supporting Project Number (TURSP-2020/150), Taif University, Taif, Saudi Arabia.

Funding Statement: This project was funded by the Taif University Researchers Supporting Projects at Taif University, Kingdom of Saudi Arabia, under Grant Number: TURSP-2020/150.

Conflicts of Interest: The authors declare that they have no conflicts of interest to report regarding the present study.

\section{References}

[1] P. Więsyk, A. Krasa, M. Słaboń and H. P. Szczęsna, "A quality of life for patients with diabetes," Journal of Education, Health and Sport, vol. 22, no. 8, pp. 276-282, 2021.

[2] S. K. Saxena, A. Elahi, S. Gadugu and A. K. Prasad, "Zika virus outbreak: An overview of the experimental therapeutics and treatment," Virus Disease, vol. 27, no. 2, pp. 111-115, 2016.

[3] M. Khan, K. Han and S. Karthik, "Designing smart control systems based on internet of things and big data analytics," Wireless Personal Communications, vol. 99, no. 4, pp. 1683-1697, 2018.

[4] M. Bhatia and S. K. Sood, "Exploring temporal analytics in fog-cloud architecture for smart OFCE healthcare," Mobile Networks and Applications, vol. 5, no. 6, pp. 1-15, 2018.

[5] T. Wu, F. Wu, J. M. Redoute and M. R. Yuce, "An autonomous wireless body area network implementation towards iot connected healthcare applications," IEEE Access, vol. 5, no. 4, pp. 11413-11422, 2017.

[6] P. J. Nachankar, M. G. Somani, D. M. Singh and S. N. Katkar, "IOT in agriculture," International Research Journal of Engineering and Technology, vol. 5, no. 4, pp. 2395-2399, 2018.

[7] V. Puri, A. Kataria and V. Sharma, "Artificial intelligence-powered decentralized framework for internet of things in healthcare 4.0," Transactions on Emerging Telecommunications Technologies, vol. 22, no. 8, pp. 276-282, 2021.

[8] S. Kawthankar and C. Raut, "A survey on smart automobiles using internet of things for digital India," International Journal of Recent Trends in Engineering \& Research, vol. 3, no. 5, pp. 27-33, 2017.

[9] K. Sharawat and S. K. Dubey, "Diet recommendation for diabetic patients using MCDM approach," Intelligent Communication, Control and Devices, vol. 22, no. 8, pp. 239-246, 2018.

[10] R. M. Zulqarnain, X. L. Xin, M. Saeed and N. Ahmad, "Recruitment of medical staff in health department by using TOPSIS method," International Journal of Pharmaceutical Sciences Review and Research, vol. 62, no. 1, pp. 1-7, 2020.

[11] M. Z. Hasan, S. Hossain, M. S. Uddin and M. S. Islam, "A generic approach for weight assignment to the decision making parameters," International Journal of Advanced Computer Science and Applications, vol. 10, no. 11, pp. 512-519, 2019. 
[12] M. Shafii, S. M. Hosseini, M. Arab, E. Asgharizadeh and F. Farzianpour, "Performance analysis of hospital managers using fuzzy AHP and fuzzy TOPSIS: Iranian experience," Global Journal of Health Science, vol. 8, no. 2, pp. 137-145, 2016.

[13] F. Rajabi, M. Jahangiri, F. Bagherifard, S. Banaee and P. Farhadi, "Strategies for controlling violence against health care workers: Application of fuzzy analytical hierarchy process and fuzzy additive ratio assessment," Journal of Nursing Management, vol. 28, no. 4, pp. 777-786, 2016.

[14] M. Zarour, M. Alenezi, M. T. J. Ansari, A. K. Pandey, R. Kumar et al., "Ensuring data integrity of healthcare information in the era of digital health," Healthcare Technology Letters, vol. 8, no. 3, pp. 66-72, 2021.

[15] M. T. J. Ansari, A. Baz, H. Alhakami, W. Alhakami, R. Kumar et al., "P-STORE: Extension of store methodology to elicit privacy requirements," Arabian Journal for Science and Engineering, vol. 64, no. 3, pp. 1-25, 2021.

[16] R. Kumar, M. Zarour, M. Alenezi, A. Agrawal and R. A. Khan, "Measuring security durability of software through fuzzy-based decision-making process," International Journal of Computational Intelligence Systems, vol. 12, no. 2, pp. 627-642, 2019.

[17] S. A. Khan, M. Alenezi, A. Agrawal, R. Kumar and R. A. Khan, "Evaluating performance of software durability through an integrated fuzzy-based symmetrical method of ANP and TOPSIS," Symmetry, vol. 12, no. 4, pp. 1-15, 2020.

[18] W. Alosaimi, R. Kumar, A. Alharbi, H. Alyami, A. Agrawal et al., "Computational technique for effectiveness of treatments used in curing sars-cov-2," Intelligent Automation \& Soft Computing, vol. 28, no. 3, pp. 617-628, 2021.

[19] K. Sahu, F. A. Alzahrani, R. K. Srivastava and R. Kumar, "Evaluating the impact of prediction techniques: Software reliability perspective," Computers, Materials \& Continua, vol. 67, no. 2, pp. 1471-1488, 2021.

[20] K. Sahu and R. K. Srivastava, "Needs and importance of reliability prediction: An industrial perspective," Information Sciences Letters, vol. 9, no. 1, pp. 33-37, 2020.

[21] F. A. Alzahrani, M. Ahmad, M. Nadeem, R. Kumar and R. A. Khan, "Integrity assessment of medical devices for improving hospital services," Computers, Materials \& Continua, vol. 67, no. 3, pp. 3619-3633, 2021.

[22] R. Kumar, M. Alenezi, M. T. J. Ansari, A. Agrawal, B. K. Gupta et al., "Evaluating the impact of malware analysis techniques for securing Web applications through a decision-making framework under fuzzy environment," International Journal of Intelligent Engineering and Systems, vol. 13, no. 6, pp. 94-109, 2020.

[23] A. Attaallah, M. Ahmad, M. T. J. Ansari, A. Pandey, R. Kumar et al., "Device security assessment of internet of healthcare things," Intelligent Automation and Soft Computing, vol. 27, no. 8, pp. 593-603, 2021.

[24] N. Kalid, A. A. Zaidan, B. B. Zaidan, O. H. Salman, M. Hashim et al., "Based real time remote health monitoring systems: A review on patient prioritization and related big data using body sensors information and communication technology," Journal of Medical Systems, vol. 42, no. 2, pp. 1-20, 2018.

[25] K. Sahu, F. A. Alzahrani, R. K. Srivastava and R. Kumar, "Hesitant fuzzy sets based symmetrical framework of decision-making for estimating the durability of web application," Symmetry, vol. 12, no. 6, pp. 1770-1792, 2020.

[26] A. Algarni, A. Attaallah, M. Ahmad, A. Agrawal, R. Kumar et al., "A fuzzy multi-objective covering-based security quantification model for mitigating risk of web based medical image processing system," International Journal of Advanced Computer Science and Applications, vol. 11, no. 1, pp. 481-489, 2020.

[27] R. Kumar, A. I. Khan, Y. B. Abushark, M. M. Alam, A. Agrawal et al., "An integrated approach of fuzzy logic, AHP and TOPSIS for estimating usable-security of web applications," IEEE Access, vol. 8, no. 8, pp. 5094450957, 2020.

[28] R. Kumar, S. A. Khan and R. A. Khan, "Durability challenges in software engineering," CrossTalk, vol. 42, no. 4, pp. 29-31, 2016.

[29] R. Kumar, M. T. J. Ansari, A. Baz, H. Alhakami, A. Agrawal et al., "A multi-perspective benchmarking framework for estimating usable-security of hospital management system software based on fuzzy logic, ANP and TOPSIS methods,"KSII Transactions on Internet and Information Systems, vol. 15, no. 1, pp. 240-263, 2021.

[30] K. Sahu and R. K. Srivastava, "Soft computing approach for prediction of software reliability," ICIC Express Letters, vol. 12, no. 12, pp. 1213-1222, 2018.

[31] R. Kumar, M. Zarour, M. Alenezi, A. Agrawal and R. A. Khan, "Measuring security durability of software through fuzzy-based decision-making process," International Journal of Computational Intelligence Systems, vol. 12 , no. 2 , pp. $627-642,2019$. 
[32] R. Kumar, S. A. Khan and R. A. Khan, "Revisiting software security: Durability perspective," International Journal of Hybrid Information Technology, vol. 8, no. 2, pp. 311-322, 2015.

[33] W. Alosaimi, A. Alharbi, H. Alyami, M. Ahmad, A. K. Pandey et al., "Impact of tools and techniques for securing consultancy services," Computer Systems Science and Engineering, vol. 37, no. 3, pp. 347-360, 2021.

[34] K. Sahu and R. K. Srivastava, "Revisiting software reliability," Advances in Intelligent Systems and Computing, vol. 802, pp. 221-235, 2019.

[35] R. Kumar, S. A. Khan and R. A. Khan, "Analytical network process for software security: A design perspective," CSI Transactions on ICT, vol. 4, no. 2, pp. 255-258, 2016.

[36] R. Kumar, S. A. Khan, A. Agrawal and R. A. Khan, "Measuring the security attributes through fuzzy analytic hierarchy process: Durability perspective," ICIC Express Letters, vol. 12, no. 6, pp. 615-620, 2018.

[37] K. Sahu and R. K. Srivastava, “"Predicting software bugs of newly and large datasets through a unified neuro-fuzzy approach: Reliability perspective," Advances in Mathematics: Scientific Journal, vol. 10, no. 1, pp. 543-555, 2021.

[38] A. H. Seh, J. F. Alamri, A. F. Subahi, A. Agrawal, R. Kumar et al., "Machine learning based framework for maintaining privacy of healthcare data," Intelligent Automation \& Soft Computing, vol. 29, no. 3, pp. 697-712, 2021.

[39] R. Kumar, A. I. Khan, Y. B. Abushark, M. M. Alam, A. Agrawal et al., "A knowledge-based integrated system of hesitant fuzzy set, AHP and TOPSIS for evaluating security-durability of web applications," IEEE Access, vol. 8, no. 8, pp. 48870-48885, 2020.

[40] R. Kumar, A. Baz, H. Alhakami, W. Alhakami, A. Agrawal et al., "A hybrid fuzzy rule-based multi-criteria framework for sustainable-security assessment of web application, Ain Shams Engineering Journal, vol. 12, no. 2, pp. 2227-2240, 2021.

[41] A. H. Seh, J. F. Alamri, A. F. Subahi, A. Agrawal, R. Kumar et al. "Hybrid computational modeling for web application security assessment," Computers, Materials \& Continua, vol. 70, no. 1, pp. 469-489, 2022.

[42] H. E. Bays, R. H. Chapman and S. Grandy, "The relationship of body mass index to diabetes mellitus, hypertension and dyslipidaemia: Comparison of data from two national surveys," International Journal of Clinical Practice, vol. 61, no. 5, pp. 737-747, 2007.

[43] Y. Shen, L. Shi, E. Nauman, P. T. Katzmarzyk, E. G. P. Haywood et al., "Association between body mass index and stroke risk among patients with type 2 diabetes," The Journal of Clinical Endocrinology \& Metabolism, vol. 105, no. 1, pp. 96-105, 2020. 